\title{
IMPLEMENTASI METODE FISHER-YATES SHUFFLE DAN FUZZY TSUKAMOTO PADA GAME 2D GOPOH BERBASIS ANDROID
}

\author{
Ekojono $^{1}$, Rizkyna Cahyaningrum ${ }^{2}$, Kadek Sarjuna Batubulan ${ }^{3}$ \\ 1,2,3 Program Studi Teknik Informatika, Jurusan Teknologi Informasi, Politeknik Negeri Malang. \\ 1ekojono2000@yahoo.co.id, ${ }^{2}$ rizkynac@gmail.com, ${ }^{3}$ kadeksuarjuna87@gmail.com.
}

\begin{abstract}
Abstrak
Perkembangan teknologi saat ini membuat banyak game yang dapat dimainkan oleh masyarakat hanya sebagai hiburan, sehingga diperlukan sebuah game yang mempunyai sisi edukatif. Salah satunya dalam game dapat diterapkan pembelajaran operasi hitung untuk melatih siswa dalam mempelajari materi operasi hitung. Pendekatan dengan visualisasi aplikasi yang menarik diharapkan dapat mampu membantu pembelajaran siswa tingkat sekolah dasar, khususnya kelas 1 dalam melatih kemampuan berhitungnya pada operasi hitung penjumlahan dan pengurangan.

Metode Fisher-Yates Shuffle merupakan algoritma yang digunakan untuk mengambil angka permutasi secara acak. Metode Tsukamoto, pada tiap aturan direpresentasikan menggunakan himpunan fuzzy, dengan menggunakan fungsi keanggotaan yang monoton. Untuk bisa menentukan nilai output crisp atau hasil tegas. Dengan menggunakan Unity 3D game engine yang mampu membuat game 2D maka diterapkanlah metode Fisher-Yates Shuffle sebagai pengacak soal dan Fuzzy Tsukamoto sebagai penentuan score akhir permainan Pengujian yang telah dilakukan menunjukkan dari hasil kuisioner bahwa game 2d Gopoh pada aspek functionality mendapat hasil sebesar 3.97 dari skala 5. Untuk aspek efficiency mendapat perolehan sebesar 4.23 dari skala 5. Untuk aspek usability mendapat perolehan 4 dari skala 5. Dari hasil rata - rata masing masing aspek tersebut dapat disimpulkan bahwa responden menjawab baik pada masing masing aspek untuk game Gopoh tersebut.
\end{abstract}

Kata kunci : fisher-yates shuffle, fuzzy tsukamoto, game, matematika, media pembelajaran, operasi hitung

\section{Pendahuluan}

\subsection{Latar Belakang}

Perkembangan game saat ini, sudah sangat pesat dan telah menjadi bagian gaya hidup. Dahulu, game hanya dijadikan sarana hiburan semata namun sekarang game telah menjadi luas fungsinya. Salah satu fungsi yang dapat didapatkan dari bermain game adalah sebagai sarana untuk mengasah ketrampilan dalam berfikir.

Matematika merupakan bidang studi yang dianggap penting oleh mayoritas masyarakat di Indonesia. Tidak jarang bidang studi ini banyak memberikan bantuan untuk mempelajari bidang studi lain yang terkait, khususnya dalam perkembangan anak sekolah dasar. Namun banyak siswa yang kesulitan dalam menguasai dasar-dasar matematika sehingga banyak pula yang gagal dalam mempelajari bidang studi ini. Dalam konteks ini yang dimaksud dengan operasi hitung matematika adalah operasi penjumlahan dan pengurangan.

Berdasarkan beberapa perubahan yang menyertai perkembangan teknologi dan informasi, maka saat ini penggunaan aplikasi pembelajaran sebagai salah satu media pembelajaran di sekolah dasar menjadi salah satu daya tarik tersendiri. Hal ini dikarenakan siswa diajak mempelajari hal yang belum pernah diketahui sebelumnya dengan melihat visualisasi yang ditampilkan. Pendekatan dengan visualisasi inilah yang diharapkan dapat mampu membantu pembelajaran siswa tingkat sekolah dasar (Putra, 2013).

Terdapat berbagai macam algoritma pengacak atau shuffling algorithms untuk memberikan teknik pengacakan pada soal sehingga soal yang keluar akan berbeda dan bisa dihasilkan tanpa pengulangan dan duplikasi algoritma untuk pengacakan soal yaitu algoritma Fisher-Yates Shuffle. Fisher-Yates Shuffle adalah sebuah algoritma untuk menghasilkan suatu permutasi acak dari suatu himpunan terhingga, hasil dari pengacakan algoritma ini memiliki tingkat probabilitas yang sama(Imam dkk., 2016).

Dalam suatu game terdapat skor untuk menentukan nilai yang didapat oleh user ketika bermain game tersebut. Pada metode Tsukamoto, implikasi setiap aturan berbentuk implikasi "SebabAkibat"/Implikasi "Input-Output" dimana antara anteseden dan konsekuen harus ada hubungannya. Setiap aturan direpresentasikan menggunakan himpunan-himpunan fuzzy, dengan fungsi keanggotaan yang monoton. Kemudian untuk menentukan hasil tegas digunakan rumus penegasan dan menghasilkan nilai rata-rata terpusat (Imam dkk., 2016). 
Berdasarkan penjelasan diatas game akan lebih baik jika terdapat sisi edukatif didalamnya dan bukan hanya untuk hiburan semata. Salah satunya dalam game dapat diterapkan pembelajaran operasi hitung untuk melatih siswa dalam mempelajari materi operasi hitung. Dengan menggabungkan game dan metode belajar seperti mencongak sehingga game yanga biasanya bersifat adiktif, namun game tersebut juga terdapat nilai edukatif. Selain itu didukung pula metode Fisher-Yates Shuffle sebagai pengacak dan Fuzzy Tsukamoto untuk penentuan skor. Dengan didukung sistem operasi Android maka diangkatlah tema mencongak dengan operasi hitung matematika menjadi sebuah game dengan judul "Implementasi Fisher-Yates Shuffle dan Fuzzy Tsukamoto Pada Game 2D Gopoh Berbasis Android". Gopoh sendiri adalah kepanjangan dari Game Operasi Hitung.

\subsection{Rumusan Masalah}

Berdasarkan latar belakang di atas, maka rumusan masalah yang dapat diambil adalah sebagai berikut:

1. Bagaimana membuat game Gopoh yang menerapkan konsep game operasi hitung didalamnya?

2. Bagaimana menerapakan metode Fisher-Yates Shuffle untuk pengacakan soal pada game Gopoh?

3. Bagaimana penentuan skor menggunakan metode Fuzzy Tsukamoto pada game Gopoh?

\subsection{Batasan Masalah}

Agar skripsi penulis yang berjudul Rancang Bangun Game 2D "Gopoh" Dengan Metode FYS dan Fuzzy Tsukamoto dapat berjalan sesuai dengan rencana dan tujuan awal, maka penulis memberikan batasan-batasan masalah yaitu :

1. Game ini berisi pertanyaan dengan operasi matematika dasar penjumlahan dan pengurangan.

2. Game ini berdimensi 2D.

3. Bekerja pada minimal versi android 4.0 atau ke atas.

4. Game ini menggunakan algoritma pengacakan yaitu algoritma Fisher-Yates Shuffle.

5. Game ini menggunakan metode Fuzzy Tsukamoto untuk perhitungan score.

6. Game ini merupakan single player.

7. Game ini ditujukan kepada siswa kelas 1 Sekolah Dasar dengan panduan buku Matematika yang menggunakan kurikulum KTSP 2006.

\subsection{Tujuan}

Tujuan dari pembuatan aplikasi game 2D Gopoh ini adalah sebagai berikut :

1. Membuat game 2D Gopoh yang dapat membantu melatih anak SD kelas 1 Sekolah Dasar matematika dalam materi operasi hitung.

2. Dapat menerapkan algoritma Algoritma FisherYates Shuffle untuk sistem pengacakan.

3. Dapat menerapkan Fuzzy Tsukamoto untuk penentuan skor pada game Gopoh.

\section{Kajian Pustaka}

\subsection{Metode Fisher Yates Shuffle}

Fisher-Yates Shuffle (dinamai berdasarkan penemunya, Ronald Fisher dan Frank Yates) digunakan untuk mengubah urutan masukan yang diberikan secara acak. Permutasi yang dihasilkan oleh algoritma ini muncul dengan probabilitas yang sama. Metode dasar yang diberikan untuk menghasilkan permutasi acak dari angka $1-N$.

Algoritma ini dinyatakan bias karena permutasi yang dihasilkan oleh algoritma ini muncul dengan probabilitas yang sama, hal ini dibuktikan dengan percobaan mengacak suatu set kartu yang dilakukan berulang. Metode Fisher-Yates secara umum adalah (Imam dkk., 2016).

1. Tuliskan angka dari 1 sampai $n$

2. Isi nilai $\mathrm{k}$ dengan bilangan acak antara 0 hingga i+1 bulatkan kebawah

3. hitung dari low end, gantikan nilai $\mathrm{k}$ dan tuliskan di tempat lain

4. Ulangi dari langkah 2 sampai semua nomor digantikan

5. Urutan angka yang tertulis di langkah 3 sekarang permutasi acak dari nomor asli.

Tabel 1 Contoh Perhitungan Algoritma Fisher Yates Shuffle

\begin{tabular}{|c|c|c|l|}
\hline $\begin{array}{c}\text { Range } \\
(\mathbf{M})\end{array}$ & $\begin{array}{c}\text { Roll } \\
(\mathbf{N})\end{array}$ & Scratch & \multicolumn{1}{|c|}{ Result } \\
\hline & & 12345 & \\
\hline $1-5$ & 3 & 1254 & $\mathbf{3}$ \\
\hline $1-4$ & 1 & $\mathbf{4 2 5}$ & $\mathbf{3} 1$ \\
\hline $1-3$ & 2 & 45 & $\mathbf{3} 12$ \\
\hline $1-2$ & 2 & 4 & $\mathbf{3 ~ 1 2} 5$ \\
\hline \multicolumn{3}{|c|}{ Hasil Pengacakan } & $\mathbf{4 3 ~ 1 2 5}$ \\
\hline
\end{tabular}

\subsection{Fuzzy Logic}

Logika fuzzy adalah cabang dari sistem kecerdasan buatan (Artificial Intelegent) yang meniru kemampuan manusia dalam berfikir ke dalam bentuk algoritma yang kemudian dijalankan oleh mesin. Algoritma ini digunakan dalam berbagai aplikasi pemrosesan data yang tidak dapat direpresentasikan statemen yang samar menjadi sebuah pengertian yang logis. Komponen-komponen 
fuzzy adalah Himpunan Fuzzy, Fuzzifikasi, Inferencing (Rule Base), Defuzzyfikasi (Kusumadewi, 2010).

\subsubsection{Fuzzy Tsukamoto}

Metode Tsukamoto, pada tiap aturan direpresentasikan menggunakan himpunan fuzzy, dengan menggunakan fungsi keanggotaan yang monoton. Untuk bisa menentukan nilai output crisp atau hasil tegas yang dicari bisa dengan cara mengubah input (berupa himpunan fuzzy yang diperoleh dari komposisi aturan fuzzy) menjadi suatu bilangan pada domain himpunan fuzzy tersebut. Metode ini disebut dengan metode defuzzifikasi (penegasan). Pada metode defuzzifikasi yang sering digunakan dalam metode Tsukamoto adalah metode defuzzifikasi rata-rata terpusat (Center Average Defuzzyfier)(Kusumadewi, 2010).

\subsection{Game}

Menurut Ernest Adams dan Andrew Rollings dalam buku Fundamentals of game desain, game merupakan salah satu jenis kegiatan bermain dengan pemainnya berusaha meraih tujuan dari game tersebut dengan melakukan aksi sesuai aturan dari game tersebut (Adam, 2007). Sebuah game memiliki beberapa elemen dasar yaitu core mechanics, user interface, gameplay.

\subsection{Android}

Android adalah sebuah sistem operasi untuk perangkat mobile berbasis linux yang mencakup sistem operasi, middleware dan aplikasi. Android menyediakan platform yang terbuka bagi para pengembang untuk menciptakan aplikasi (Adam, 2007).

\section{Metode Penelitian}

Pengembangan game 2d "Gopoh" dilakukan dengan mengaplikasikan metodologi Multimedia Development Life Cycle (MDLC). Pengembangan multimedia harus memiliki tahapan-tahapan yang terancang dengan baik dan runtu agar produk yang dihasilkan memiliki kualitas yang baik dan tepat digunakan sebagai media pembelajaran. Tahapan pengembangan dalam Multimedia Development Life Cycle (MDLC) ini terdapat enam tahap yaitu :

\subsection{Konsep}

Tahapan pada proses ini meliputi pembutan konsep mengenai game akan dibuat.

\subsection{Perancangan}

Pada fase desain (perancangan) dimulai dengan membuat garis besar dari tampilan dan informasi yang akan ditampilkan dilayar. Pada tahap ini menggunakan storyboard untuk menggambarkan deskripsi tiap scene, dengan menjelaskan semua objek multimedia dan tautan pada scene yang ditampilkan. Flowchart digunakan untuk menggambarkan aliran dari satu scene ke scene lain.

Tabel 2. Story Board Game Gopoh

\begin{tabular}{|c|c|}
\hline Storyboard & Deskripsi \\
\hline & $\begin{array}{l}\text { Tampilan Spalsh } \\
\text { Screeen } \\
\text { Pada tampilan Splash } \\
\text { Screen adalah tampilan } \\
\text { ketika pertama kali } \\
\text { membuka game Gopoh } \\
\text { ini. }\end{array}$ \\
\hline 1 & $\begin{array}{l}\text { Tampilan Menu } \\
\text { Mulai : untuk } \\
\text { memasuki game. } \\
\text { Petunjuk : untuk } \\
\text { memberi info kepada } \\
\text { user bagaimana cara } \\
\text { bermainnya } \\
\text { Lain - lain : untuk } \\
\text { melihat Skor Tertinggi } \\
\text { dan Info Mengenai } \\
\text { Game ini. }\end{array}$ \\
\hline $\begin{array}{l}\text { ENGURANGAN } \\
\text { CAMPURAN }\end{array}$ & $\begin{array}{l}\text { Pada saat tombol Play di } \\
\text { mulai aka nada } 2 \text { opsi } \\
\text { yaitu } \\
\text { Penjumlahan : soal } \\
\text { yang dikeluarkan adalah } \\
\text { penjumlahan } \\
\text { Pengurangan : soal } \\
\text { yang dikeluarkan adalah } \\
\text { pengurangan } \\
\text { Campuran : soal yang } \\
\text { dikeluarkan adalah } \\
\text { penjumlahan dan } \\
\text { pengurangan dan } \\
\text { penjumlahan denga tiga } \\
\text { operand }\end{array}$ \\
\hline (11) X & $\begin{array}{l}\text { Permainan } \\
\text { User akan memainkan } \\
\text { operasi hitung } \\
\text { matematika, dalam } \\
\text { contoh adalah operasi } \\
\text { penjumlahan. Terdapat } \\
\text { batas waktu untuk user } \\
\text { menjawa setiap soalnya, } \\
\text { apabila waktu habis, } \\
\text { dinyatakan game over. } \\
\text { Terdapat button pause } \\
\text { untuk menghentikan } \\
\text { sejenak permainan. }\end{array}$ \\
\hline
\end{tabular}




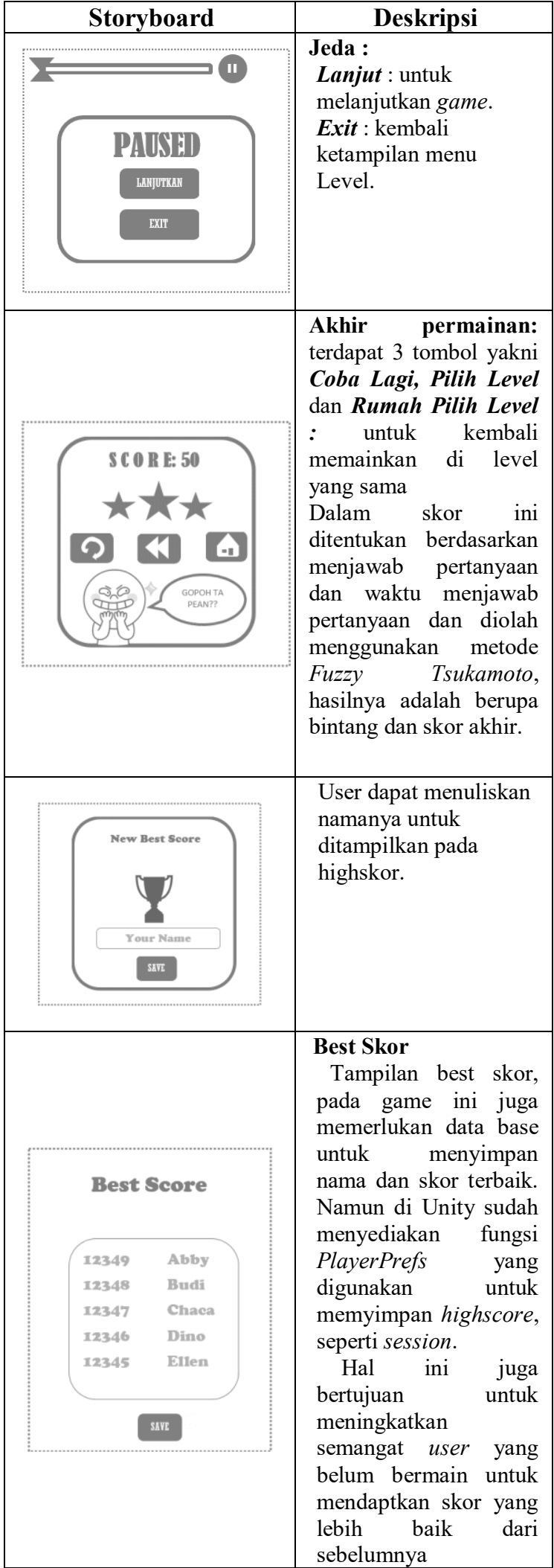

Terdapat beberapa tahapan dalam menentukan score dengan menggunakan metode Fuzzy Tsukamoto. Tahap pertama adalah adalah pembentukan Himpunan Fuzzy Logic. Setelah perancangan pembuatan himpunan keanggotaan selesai dibuat selanjutnya adalah pembuatan Rule.
Berikut adalah rancangan variable input dan output untuk fungsi keanggotaan waktu, point, dan score.

Tabel 3. Variabel Input

\begin{tabular}{|l|l|l|}
\hline Variabel & \multicolumn{1}{|c|}{$\begin{array}{c}\text { Himpunan Input } \\
\text { Fuzzy }\end{array}$} & Range \\
\hline \multirow{3}{*}{ Waktu } & Cepat & $0-100$ \\
\cline { 2 - 3 } & Sedang & $50-150$ \\
\cline { 2 - 3 } & Lambat & $100-150$ \\
\hline \multirow{3}{*}{ Point } & Sedikit & $0-66.6$ \\
\cline { 2 - 3 } & Sedang & $33.3-100$ \\
\cline { 2 - 3 } & Banyak & $66.6-100$ \\
\hline
\end{tabular}

Tabel 4. Variabel Output

\begin{tabular}{|l|l|c|}
\hline Variabel & \multicolumn{1}{|c|}{$\begin{array}{c}\text { Himpunan } \\
\text { Output Fuzzy }\end{array}$} & Range \\
\hline Scoring & Kurang & $0-30$ \\
\cline { 2 - 3 } & Sedang & $30-60$ \\
\cline { 2 - 3 } & Mahir & $60-100$ \\
\hline
\end{tabular}

Berikut adalah Penentuan Aturan (Rules)

Tabel 5. Komposisi Aturan

\begin{tabular}{|l|l|l|l|}
\hline \multicolumn{1}{|c|}{ IF } & $\begin{array}{c}\text { KECEPATAN } \\
(\mathrm{A})\end{array}$ & $\begin{array}{c}\text { POINT } \\
(\mathrm{P})\end{array}$ & $\begin{array}{c}\text { SCORE } \\
(\mathrm{S})\end{array}$ \\
\hline R1 & CEPAT & SEDIKIT & CUKUP \\
\hline R2 & CEPAT & SEDANG & CUKUP \\
\hline R3 & CEPAT & BANYAK & BAIK \\
\hline R4 & SEDANG & SEDIKIT & KURANG \\
\hline R5 & SEDANG & SEDANG & CUKUP \\
\hline R6 & SEDANG & BANYAK & CUKUP \\
\hline R7 & LAMBAT & SEDIKIT & KURANG \\
\hline R8 & LAMBAT & SEDANG & KURANG \\
\hline R9 & LAMBAT & BANYAK & CUKUP \\
\hline - Fungsi Keanggotaan Waktu & \\
\hline \multicolumn{3}{|l}{}
\end{tabular}

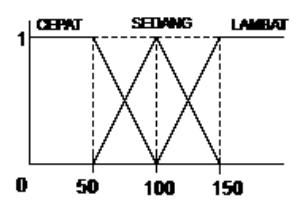

- Fungsi Keanggotaan Point

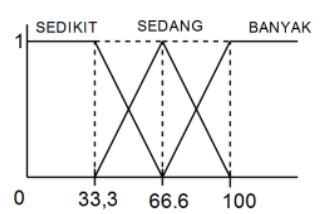

- $\quad$ Fungsi Keanggotaan Score

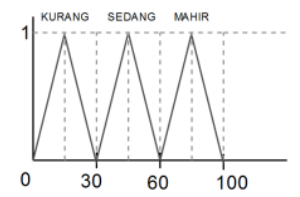

\subsection{Material Collecting}

Pengumpulan bahan adalah tahapan dimana mengumpulkan bahan yang seuai dengan kebutuhan 
yang telah direncanakan. Bahan-bahan yang dibutuhkan adalah sebagai berikut:

- Gambar : gambar digunakan asset dalam pembuatan, adapun asset yang dibutuhkan adalah asset puzzle, asset button, asset background, asset bangun dan asset petunjuk game.

- Audio : file audio digunakan sebagai music latar game, dubbing pengenalan bangun, dan suara efek button.

- Software : kebutuhan perangkat lunak yang digunakan untuk menujang keperluan pembuatan game seperti game engine Unity, editor gambar CorelDraw X5, dan editor music AudaCity.

\subsection{Assembly}

Tahap assembly (pembuatan) adalah tahap pembuatan semua objek atau bahan multimedia. Pembuatan aplikasi berdasarkan storyboard, flowchart, dan struktur navigasi yang berasal pada tahap desain. Prosen pembutan diawali dengan pembuatan asset desain User Interface. Software yang digunakan dalam pembuatan $U I$ adalah CorelDraw X5.

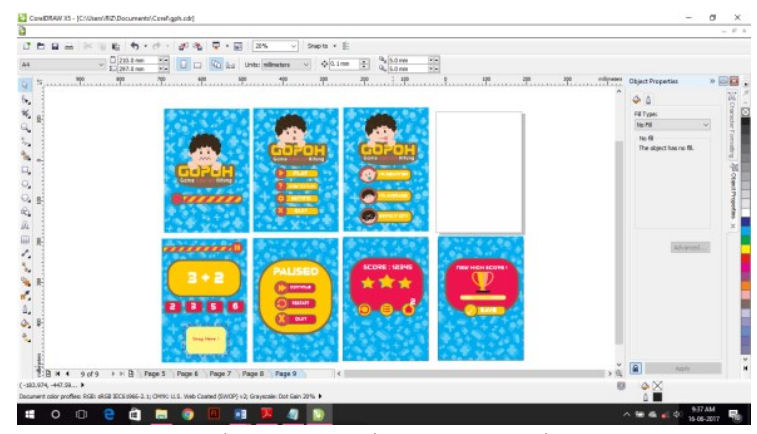

Gambar 1. Pembuatan Desain UI

Dalam proses pembuatan game ini menggunakan game engine Unity 5.3.1. Unity Merupakan aplikasi game engine yang dapat digunakan untuk membuat game 2D atau 2D. Bahasa pemrograman yang dapat digunakan di Unity adalah C\#.

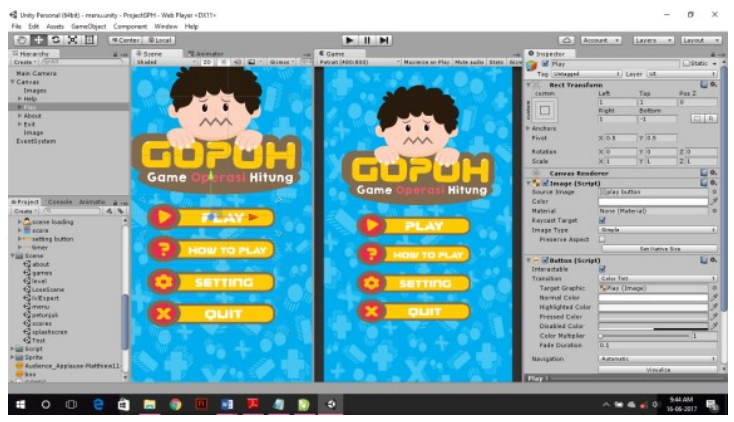

Gambar 2. Pembuatan Game di Unity

Pengacakan yang diterapkan pada aplikasi ini adalah mengacakan soal dan jawaban yang dikeluarkan ketika setiap level dimainkan. Berikut Potongan script dari pengacakan scene.

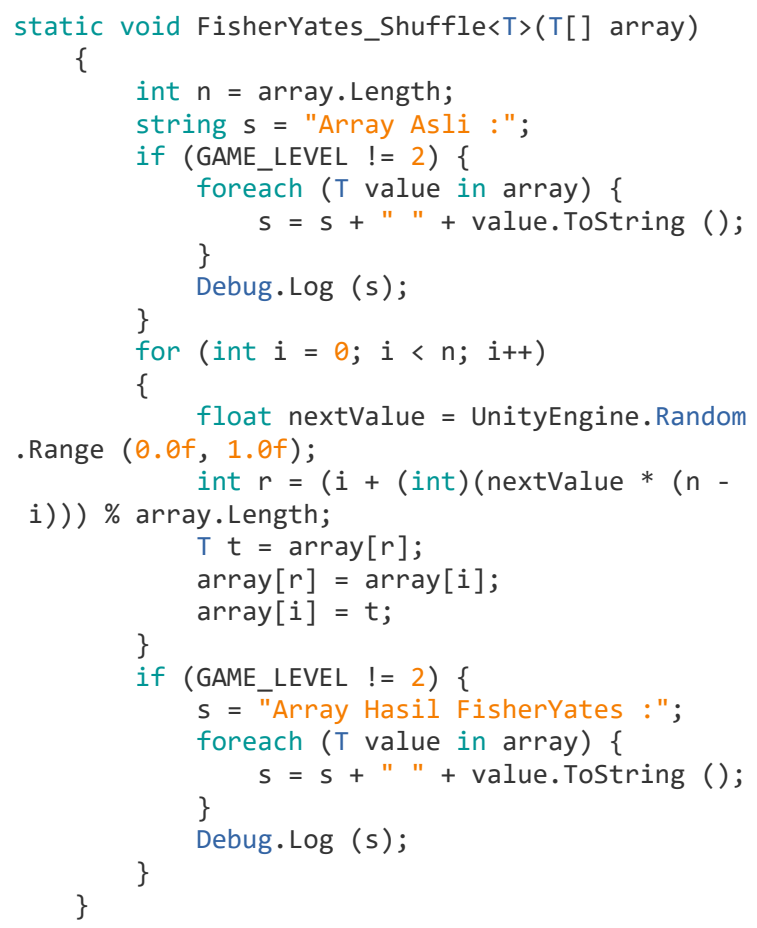

\subsection{Testing}

Pengujian (testing) pada game Gopoh dilakukan dengan melakukan pengujian alpa dan betha. Pengujian alpha dilakukan setelah proses pembuatan, pengujian alpha menggunakan metode pengujia BlackBox. Metode ini dilakukan dengan menjalankan aplikasi, kemudian dilihat apakah terjadi kesalahan ketika menjalankan fungsi yang sudah teredia. Pengujian betha melibatkan pengguna akhir yaitu anak-anak atau masyarakat umum. Pada saat pengujian juga dilakukan penyebaran kuesioner mengenai aplikasi ini, kuesioner yang diberikan berisi pertanyaan yang berhubungan dengan kepuasan dan tercapainya tujuan dari pembuatan game Gopoh ini.

\subsection{Distribution}

Pada tahap ini aplikasi akan disimpan pad media penyimpanan yang dapat diunduh oleh masyarakat umum. Tahap ini juga terdapat proses evaluasi terhadap produk agar dapat dikembangnkan menjadi lebih baik. Evaluasi yang didapat dapat dimasukkan untuk tahap concept pada pengembangan selanjutnya.

\section{Hasil dan Pembahasan}

\subsection{Hasil}

Berikut adalah hasil dari aplikasi yang telah di compile di smartphone android 

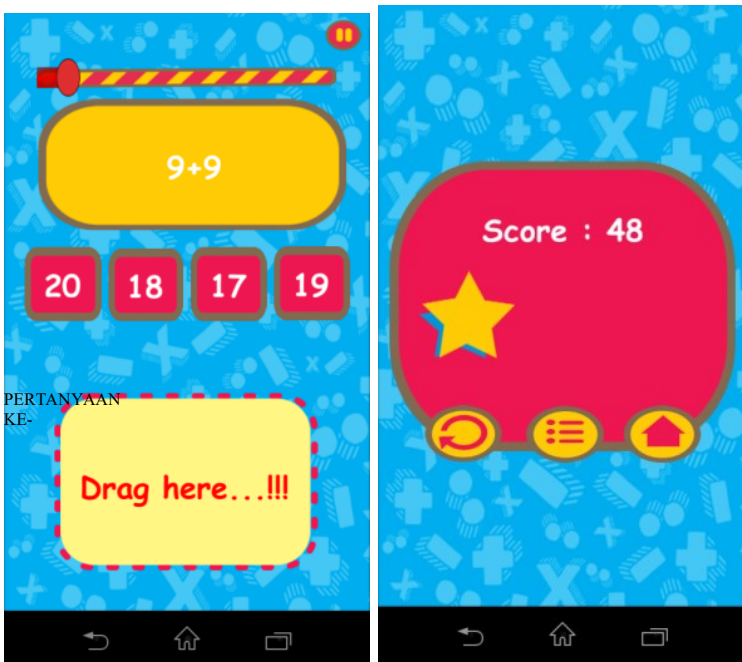

Gambar 3. Tampilan pada smartphone

Berikut adalah hasil pengujian Algoritma Fisher Yates Shuffle

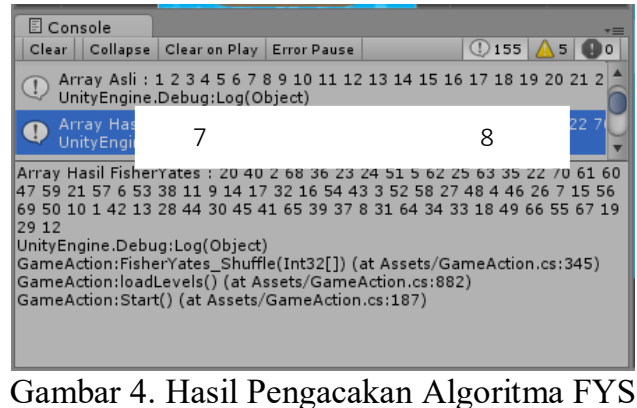

Dari hasil diatas telah dilalukan pengijian terhadap Algoritma Fisher-Yates yang dilakukan dengan cara menampilkan di console Unity. Dan dapat dilihat, algoritma FYS berhasil diterapkan.

Berikut adalah hasil pengujian dari algoritma Fuzzy Tsukamoto

\begin{tabular}{|c|}
\hline 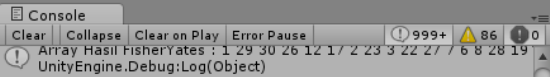 \\
\hline $\begin{array}{l}\text { (1) } 0.19960070 .8003993 \\
\text { UnityEngine.Debug:Log(Object) }\end{array}$ \\
\hline $\begin{array}{l}\text { (1.) Input Point28 MaxScore30 } \\
\text { UnityEngine.Debug:Log(Object) }\end{array}$ \\
\hline $\begin{array}{l}\text { (1) } 0.54 \quad 0.46 \\
\text { UnityEngine.Debug:Log(Object) }\end{array}$ \\
\hline $\begin{array}{l}\text { (1) Waktu : } 77 \\
\text { Unity Engine.Debug:Log(Object) }\end{array}$ \\
\hline (1) 0.19960070 .8003993 \\
\hline $\begin{array}{l}\text { (1) Z1: 20Z2: 27.98403Z3: 78.4Z4: 60Z5: 27.98403Z6: 41.6Z7: 60Z8: } \\
\text { UnityEngine.Debug:Log(Object) }\end{array}$ \\
\hline 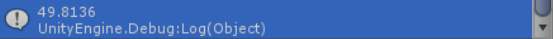 \\
\hline $\begin{array}{l}49.8136 \\
\text { Unity Engine.Debug: Log(Object) } \\
\text { Gameaction: hitungurzuzy(Single, Single) (at Assets/GameAction.cs: 312) } \\
\text { GameAction:tamoilsoal() (at Assets/GameAction.cs:527) }\end{array}$ \\
\hline
\end{tabular}

Gambar 5. Hasil Perhitungan Fuzzy Tsukamoto

Berdasarkan dari gambar diatas dapat diketahui bahwa Fuzzy Tsukamoto berhasil diterapkan untuk menentukan score akhir berdasarkan input waktu dan point dari aplikasi.

Selanjutnya adalah pembahasan yang dilakukan adalah membahas hasil kuisioner yang sebelumnya telah dijawab oleh responden. Dari aspek Functionality didapatkan hasil yang ditunjukkan pada Gambar 6 berikut.

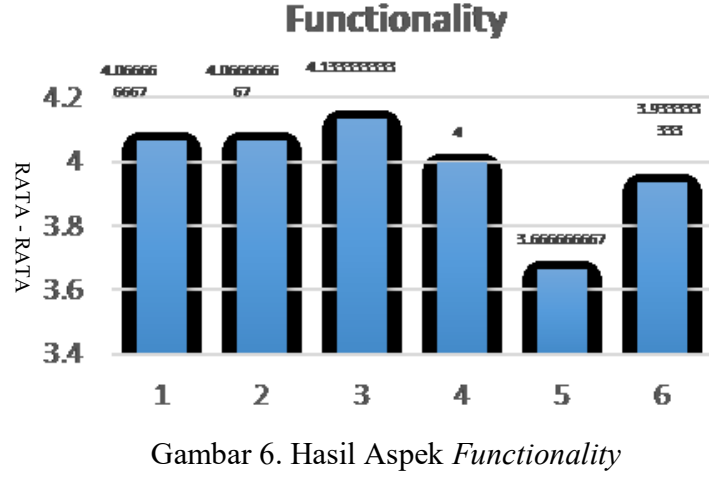

Dapat dilihat dari grafik tersebut semuanya menjawab baik. Selanjutnya pada aspek Efficiency diperoleh hasil yang ditunjukkan pada Gambar 7 berikut.

\section{Efficiency}

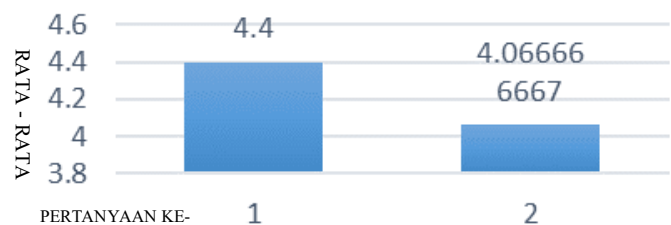

Gambar 7. Hasil Aspek Efficiency

Berdasarkan grafik diatas dapat diketahui responden menjawab 4 yang dapat disimpulkan bahwa untuk pertanyaan 7 dan 8 memiliki respon baik. Berikut ini adalah hasil untuk aspek usability yang ditunjukkan pada Gambar 8 dibawah ini.

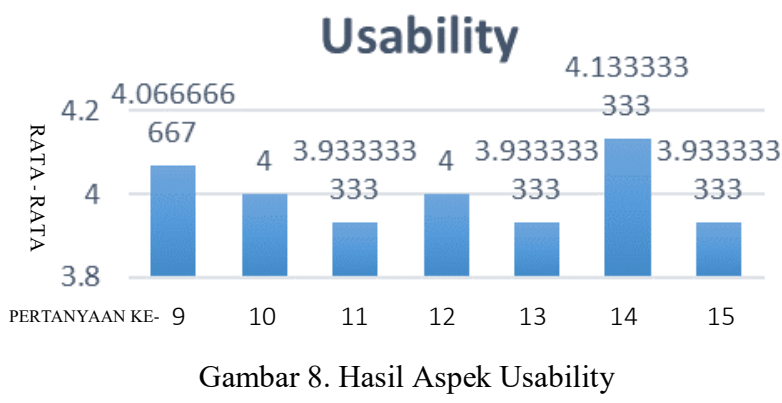

Pada hasil tersebut terlihat bahwa untuk pertanyaan nomor 9 sampai dengan nomor 15 mendapat hasil yang baik.

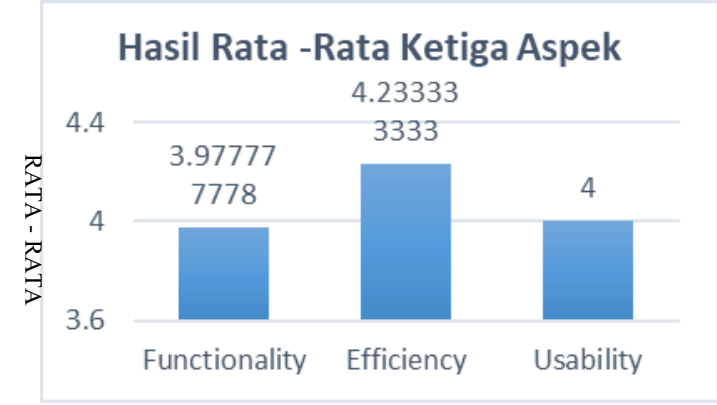

Gambar 9. Hasil Rata-Rata Tiap Aspek

Berdasarkan hasil rata rata dari setiap aspek yaitu aspek Functionality, Efficiency dan Usability 
didapatkan perolehan rata - rata dari masing masing aspek. Dari aspek functionality mendapat hasil sebesar 3.97 dari skala 5. Untuk aspek efficiency mendapat perolehan rata-rata sebesar 4.23 dari skala 5. Untuk aspek usability mendapat perolehan 4 dari skala 5. Dari hasil rata - rata masing masing aspek tersebut dapat disimpulkan bahwa responden menjawab baik pada masing masing aspek untuk game Gopoh tersebut.

\section{Penutup}

\subsection{Kesimpulan}

Kesimpulan yang didapatkan dari pembuatan skripsi "Implementasi Fisher-Yates Shuffle dan Fuzzy Tsukamoto Pada Game 2D Gopoh Berbasis Android" adalah sebagai berikut :

1. Implementasi metode pengacakan menggunakan algoritma Fisher-Yates Shuffle berhasil diterapkan di dalam game Gopoh sebagai pengacak soal dan jawaban yang akan muncul dalam setiap permainan.

2. Implementasi metode Fuzzy Tsukamoto pada sistem berhasil diterapkan pada game Gopoh sebagai penentuan score dan menampilkan bintang.

3. Dari aspek functionality mendapat hasil sebesar 3.97 dari skala 5. Untuk aspek efficiency mendapat perolehan rata-rata sebesar 4.23 dari skala 5. Untuk aspek usability mendapat perolehan 4 dari skala 5. Dari hasil rata - rata masing masing aspek tersebut dapat disimpulkan bahwa responden menjawab baik pada masing masing aspek untuk game Gopoh tersebut.

\subsection{Saran}

Dari hasil serta uraian pada bab-bab sebelumnya terhadap game 2D Gopoh maka saran yang diberikan penulis untuk pengembangan game ini adalah:

1. Game 2D Gopoh dapat dikembangkan dari banyak sisi. Dari sisi pemberian variasi soal, variasi operasi hitung dan lain sebagainya.

2. Pengembangan selanjutnya algoritma bisa pula dikembangakan dengan algoritma lain yang tentunya sesuai dengan kebutuhan game.

3. Penambahan level juga bisa dikembangkan sehingga user dapat bermain dengan variasi permainan yang berbeda.

4. Dalam pengembangan selanjutnya pendekatan pengguna bisa dirubah dengan menambah sequence pengguna ke kelas lain selain kelas 1 Sekolah Dasar.

5. Untuk pengembangan selanjutnya game Gopoh yang bertipe single player ini dapat pula dijadikan game dengan tipe multiplayer sehingga antar user dapat saling mengadu kemampuan dalam kecepatan berpikir.
6. Untuk pengacakan pada pengembangan selanjutnya dapat mengembangkan pengacakan latar musik yang berbeda. Sehingga ketia user memulai permainan, musik yang muncul akan acak pula.

\section{Daftar Pustaka:}

Adams, Ernest., \& Andrew Rollings. 2007.’Fundamentals of Game Desain". Pearson Education, Inc. New Jersey

Imam Haditama, Cepy Slamet, Deny Fauzy Rahman. "Implementasi Algoritma Fisher-Yates Dan Fuzzy Tsukamoto Dalam Game Kuis Tebak Nada Sunda Berbasis Android”. JOIN, Volume I, No. 1, Juni 2016

Kusumadewi, S., dan Purnomo, S.2010. “Aplikasi Logika Fuzzzy untuk Pendukung Keputusan”. Yogyakarta: Graha Ilmu.

Putra, Samuel Poernomo, 2013. "Pembuatan Media Pembelajaran Operasi Hitung Matematika Untuk Siswa Kelas VI Sekolah Dasar”. Jurnal Ilmiah Mahasiswa Universitas Surabaya Vol. 2. 